\title{
A TERCEIRIZAÇÃO NO CONTEXTO DA REFORMA TRABALHISTA: conceito amplo e possibilidades metodológicas
}

\author{
Alisson Droppa * \\ Magda Barros Biavaschi * * \\ Marilane Oliveira Teixeira ***
}

\begin{abstract}
O artigo, fundamentado em pesquisas realizadas no âmbito do CESIT/Unicamp, traz à discussão a necessidade de se adotar conceito amplo para a terceirização que a abarque em seus aspectos internos e externos, expressos e burlados, bem como discorre sobre a importância de se buscar construir uma metodologia que permita se possa melhor e mais amplamente medir essa forma de contratar. Para tanto, aborda algumas das formas de aferição, sugerindo a combinação de iniciativas para mapeá-la. Discute, também, os impactos da terceirização aprovada pela reforma trabalhista brasileira sem limites para quaisquer atividades, ampliando as dificuldades para sua mensuração, trazendo maiores desafios na busca da construção dessa metodologia. Ainda, a partir da análise de um conjunto de instrumentos coletivos dos anos 2016 e 2019, analisa como a terceirização foi sendo tratada por esses instrumentos, sugerindo, inclusive, que a terceirização irrestrita e sua ampliação no contrato temporário foram absorvidas nessas negociações.

Palavras-Chave: Terceirização. Regulamentação. Contrato de Trabalho. Reforma Trabalhista. Mundos do Trabalho.
\end{abstract}

\section{INTRODUÇÃO}

Neste ano de 2021 vivem-se momentos de grave crise que, gerada no campo econômico, extrapola essa dimensão. O fenômeno da exclusão social acelera-se. As desigualdades aprofundam-se. O processo de cisão da classe trabalhadora intensifica-se. As organizações sindicais perdem força em meio à ampliação da terceirização, da informalidade e da legalização de formas de contratar que transformam trabalhadores em "empresários de si próprios", PJs, MEIs, "por conta própria”, fazendo da simulação a legalidade (Filgueiras; Cavalcante, 2020). Os reflexos nas negociações coletivas e nos direitos conquistados são decorrências. No

* Universidade Estadual de Campinas.

Rua Cora Coralina, 100 - Cidade Universitária Zeferino Vaz. Barão Geraldo. Cep: 13083-896. Campinas - São Paulo - Brasil. alissondroppa@gmail.com https://orcid.org/0000-0001-6568-9871

** Universidade Estadual de Campinas.

Rua Cora Coralina, 100 - Cidade Universitária Zeferino Vaz. Barão Geraldo. Cep: 13083-896. Campinas - São Paulo-Brasil.magdabia@terra.com.br, https://orcid.org/0000-0002-4175-5229

*** Universidade Estadual de Campinas

Rua Cora Coralina, 100 - Cidade Universitária Zeferino Vaz. Barão Geraldo. Cep: 13083-896. Campinas - São Paulo - Brasil.mari@uol.com.br,

https://orcid.org/0000-0003-0246-9147 loca-locadas plataformas digitais, o tempo trabalhado é desencarnado (Berardi, 2020, p.191), sem direitos e sem demandas. A alardeada autonomia de trabalhadores submetidos ao comando de estruturas monopolistas é substituída pela intensificação das horas trabalhadas, da submissão e do controle (Belluzzo, 2020). Nesse cenário, as instituições fragilizam-se (Altvater, 1987). São tempos em que os interesses privados subjugam o sentido do público e em que os indivíduos, pressionados pelo desemprego, pelo desalento, pela insegurança quanto à sobrevivência, aparecem destituídos do princípio da esperança e da capacidade de organização coletiva, criando-se ambiente propício para que uma onda conservadora tome conta do imaginário popular (Oliveira, 1996).

A pandemia decorrente da expansão da COVID - 19 chegou oficialmente no Brasil em março de 2020, escancarando as fragilidades dos arranjos internacionais do capitalismo e as históricas desigualdades que costuram o tecido social brasileiro, aprofundando-as. Em meio a esse cenário, em 16 de junho de 2020a página de internet do Supremo Tribunal Federal, STF, noticiou o julgamento virtual de duas Ações 
Diretas de Inconstitucionalidade (ADIs5685 e 5695) tendo como objeto da Lei $\mathrm{n}^{0} 13.429$, de 2017, "Lei da Terceirização", sancionada pelo então presidente Michel Temer em 31 de março daquele ano. Essa lei modificou a Lei $\mathrm{n}^{\mathrm{o}}$ 6019/74, "Lei do Trabalho Temporário", que regulamentou as chamadas relações "trilaterais" ou "assimétricas". Ainda que o termo terceirização ainda não estivesse cunhado, essa lei abriu as portas legais para o ingresso de um terceiro no binômio empregado $\mathrm{x}$ empregador, expressando forma de contratar que, mais tarde, seria conhecida como terceirização e cujo potencial altamente precarizador tem sido apontado em textos e pesquisas acadêmicas (Biavaschi; Baltar, 2009; Biavaschi; Baltar, 2012; Druck, 2016; Basualdo; Morales, 2014; Del Bono; Bulloni, 2019).

A Lei $n^{0}$ 13.429/17 teve origem em projeto de lei encaminhado pelo Poder Executivo em 1998para alterar aspectos da Lei $\mathrm{n}^{\circ}$ 6.019/74: PL $\mathrm{n}^{\mathrm{o}}$ 4302/98. Com substitutivo aprovado no Senado em dezembro de 2002, esse PL retornou à Câmara para ser apreciado. No início do governo de Luiz Inácio Lula da Silva, tramitava em regime de urgência. Diante de forte reação das organizações sindicais de trabalhadores, movimentos sociais e entidades trabalhistas, o Presidente Lula encaminhou a Mensagem $n^{\circ}$ 389/03 solicitando seu arquivamento. Apenas a urgência foi retirada. ${ }^{1}$

O deputado Sandro Mabel (MDB/GO), নี aliás, o autor do PL n ${ }^{\circ}$ 4330/04 que buscava N ampliar as possibilidades do uso da terceirizoção, foi designado relator do PL no 4302/98. E Em outubro de 2008, seu parecer favorável Ii ao substitutivo do Senado foi aprovado na ¿. Comissão de Trabalho da Câmara. Tratava-se Æ̛ de projeto que, contrapondo-se à Súmula $\mathrm{n}^{\circ}$ $\therefore$ 331/93 do Tribunal Superior do Trabalho, TST, estendia, no trabalho temporário, a terceirização às atividades fim, desvirtuando o caráter excepcional dessa forma de contratar. Desde

${ }^{1}$ Em setembro de 2008, a Executiva da Central Única dos Trabalhadores - CUT, reiterou a necessidade da retirada por meio do Ofício Circular 05015087375/08/SG/CUT. maio de 2011, esse PL “dormia” na Comissão de Constituição e Justiça, CCJC, aguardando agenda para votação (Biavaschi; Santos; Droppa, 2014; Biavaschi; Teixeira, 2015; Biavaschi; Teixeira, 2018). Seu abrupto desengavetar se deu justo quando o PL $\mathrm{n}^{\circ} 4330 / 04,{ }^{2}$ de autoria do mesmo deputado, Sandro Mabel, aprovado pela Câmara em 2015,aguardava na Comissão de Direitos Humanos, CDH, do Senado(PLC $\left.n^{\circ} 30 / 2015\right)$, parecer do relator, Senador Paulo Paim (PT/RS).

Objeto de audiências públicas realizadas pelo Senador Paim em praticamente todos os estados da federação, em conjunto com o Fórum Nacional em Defesa dos Direitos dos Trabalhadores Ameaçados pela Terceirização, FÓRUM, ${ }^{3}$ e com o parecer opinando pelo arquivamento prestes ser apresentado, a notícia do desengavetar do PL n ${ }^{\circ} 4302 / 98$ movimentou as Centrais Sindicais. E conquanto tenha o então Presidente da Câmara, deputado Rodrigo Maia (DEM-RJ), afirmado que seria respeitada a tramitação do PLC n $30 / 15$, o PL 4302/98 foi votado e aprovado em março de 2017. Trata-se da Lei no 13.429/17, sancionada quando já tramitava no Senado a reforma trabalhista. Em 2017, a Rede Sustentabilidade ${ }^{4}$ ajuizou a ADI $n^{\circ} 5685$, alegando, em síntese, que essa lei feria o princípio constitucional da proteção ao trabalho e que a terceirização na administração pública violaria a regra do concurso público. Apensada à ADI nº 5695, da Confederação Nacional dos Trabalhadores na Indústria Química, CNTQ, e da Confederação Nacional dos Trabalhadores nas Indústrias Têxtil, Vestuário, Couro e Calçados, Conaccovest, por sete votos a quatro o STF acatou o argumento da Advo-

${ }^{2}$ PL estendendo a terceirização, indiscriminadamente, às atividades-fim das tomadoras de serviços.

${ }^{3}$ O FÓRUM, integrado pelas Centrais Sindicais, Confederações, Federaçõ̃es, Sindicatos, entidades de representação do mundo do trabalho (ANAMATRA, ALJT, ANPT, SINAIT), movimentos, Centros de Pesquisa (Unicamp, UNB, outros), criado em 2011 ao avanço do PL 4330/04 (PLC30/15 no Senado) que estendia a terceirização a todas as atividades da tomadora, articulou setores contrários a essa forma de contratar.

${ }^{4}$ Partido político com registro definitivo obtido em 22 de setembro/2015. 
cacia-Geral do Senado Federal de regularidade do processo legislativo. ${ }^{5}$

Com esse registro introdutório, assinala-se a importância de se adotar conceito amplo de terceirização que abarque a complexidade do fenômeno e de se buscar metodologia que possa mais bem medi-lo. Ainda, olhando para alterações introduzidas pela reforma no campo da ação sindical, o artigo analisa algumas normas coletivas que contemplam a terceirização e seus significados, apontando, a final, para a relevância de se pensar em uma regulação pública de proteção social ao trabalho que a todos possa incorporar.

\section{O CAPITALISMO, O CONTEXTO ECONÔMICO E A TERCEIRIZAÇÃO}

Como abordam textos anteriores (Biavaschi; Teixeira; Droppa, 2020; Biavaschi; Droppa; Alves, 2021), tem sido crescente a subordinação do capital produtivo à lógica das finanças. Sem fronteiras, os estados nacionais são arrastados para uma intrincada rede de relações de poder e dominação, fragilizando as políticas de proteção social e de direitos. As pressões pela flexibilização das normas públicas de proteção se intensificam. Somam-se a isso as mudanças estruturais e a reestruturação nos processos organizacionais, com racionalização do uso do tempo. O capital passa a dispor do indivíduo em tempo integral, mas de forma instável e irregular, adotando novas formas de contratar, de definir a jornada e a remuneração. Nessa démarche, os direitos conquistados e as instituições aptas a concretizá-los são entraves a serem eliminados.

Nas décadas de 1980 e 1990, a livre circulação mundial do capital financeiro tornou-se predominante. A riqueza financeira passou a se movimentar "livremente" para países garantidores de mais rentabilidade, invadindo

${ }^{5}$ Pela constitucionalidade Ministros: Gilmar Mendes, Alexandre de Moraes, Carmen Lúcia, Luiz Fux, Barroso, Dias Toffoli e Celso de Mello. Vencidos Ministros: Marco Aurélio, Fachin, Lewandowski e Rosa Weber. a gestão do setor produtivo, sobretudo nas grandes corporações, entrelaçando-se o capital produtivo ao fictício (Braga, 1997). Essa articulação entre sistema financeiro e produtivo passou a coordenar os investimentos e os progressos tecnológicos em estratégias de expansão das grandes empresas mundiais. Com o conhecimento tecnológico cada vez mais restrito aos países avançados, os periféricos limitaram-se à produção de itens com baixo valor agregado. Em decorrência, em regra, seus parques produtivos industriais desestruturaram-se diante de agressiva concorrência e suas empresas submeteram-se às diretrizes mundiais de gestão, adotando processos de reorganização e de redução de custos. ${ }^{6}$

O amplo processo de reestruturação do capital forjou seus espaços, impactando no trabalho e na organização dos trabalhadores. Os temas do custo do trabalho e da insegurança jurídica passaram a ser fortemente invocados para sustentar, por exemplo, que a política de crescimento salarial é incompatível com a retomada da atividade econômica e do emprego. No bojo desse processo, em que as estruturas organizacionais são enxugadas nos mercados interno e externo, a terceirização consolidou-se como estratégia de redução de custos e de busca de lucratividade. Daí os mecanismos que permitem mais flexibilidade às formas de contratar, remunerar e de uso da força de trabalho e que limitam a ação das instituições públicas do trabalho (Justiça do Trabalho, sistemas de fiscalização e organizações sindicais). Nessa caminhada, a força normativa da constituição é abalada e direitos são atingidos, inclusive pela via da interpretação. Para alguns autores, vivem-se tempos em que o estado é capturado pelos interesses das grandes corporações internacionais e das finanças (Belluzzo; Galipolo, 2017). Em regra, opondo as transformações organizacionais e tecnológicas à redução de empregos, os debates apresentam as

\footnotetext{
${ }^{6}$ Essas considerações estão presentes no Relatório Científico Parcial da pesquisa "A Justiça do Trabalho e a Terceirização", encaminhado à FAPESP em 30 de outubro de 2008.
} 
novas formas de uso da força de trabalho como \inevitáveis $\square$, entre elas a terceirização, reforçando-se a ideia de que a liberação das forças que impulsionam a acumulação de capital é um movimento "natural" e "irreversível” em direção ao progresso e à autonomia dos indivíduos (Belluzzo, 2013, p.33).

A ênfase nos contratos individuais como fonte prevalente da produção das normas trabalhistas e a introdução, por exemplo, do "autônomo exclusivo" (em regra, relação de emprego disfarçada), do contrato intermitente, da terceirização irrestrita, inserem-se nessa complexidade. O argumento é o de que a "rigidez" da legislação impede os investimentos, a retomada da economia e a geração de empregos (Biavaschi; Teixeira, 2018). Fundamentada em falsas ideias, a reforma trabalhista brasileira de 2017 legitimou acordos individuais e coletivos redutores de direito (Biavaschi, 2005; Biavaschi, 2007). Os resultados não têm sido bons. O desemprego aumentou, os salários e as condições de trabalho e de segurança foram rebaixados. A fragilização das organizações sindicais impacta de forma negativa as negociações coletivas, realidade que a ampliação da terceirização para quaisquer atividades não tratou de melhorar.

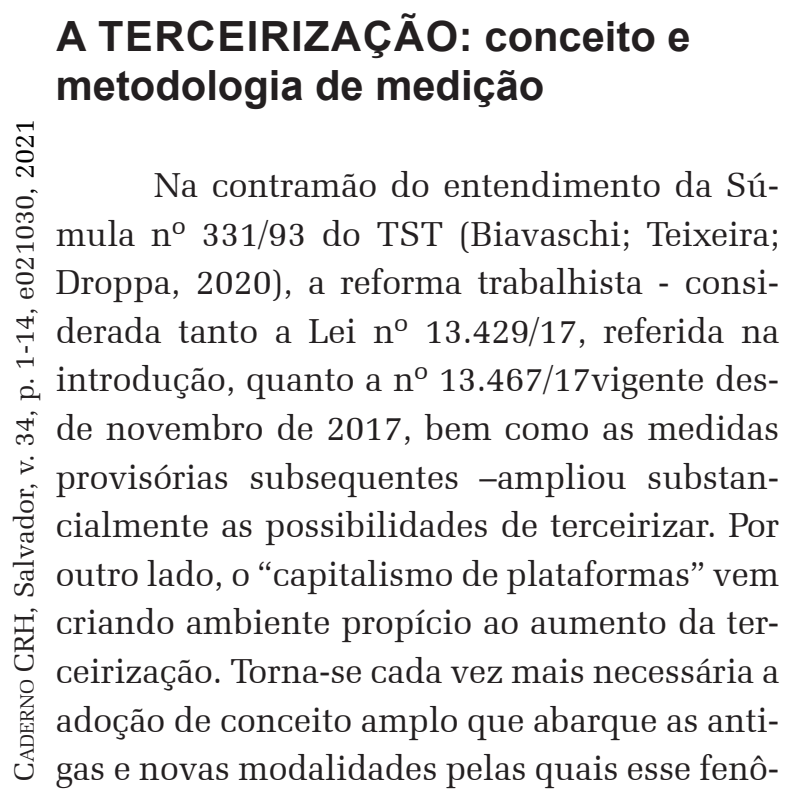

meno se apresenta no mundo do trabalho, muitas vezes de forma burlada (Biavaschi; Santos; Droppa, 2014; Biavaschi, Teixeira, 2015), bem como de uma metodologia que considere essas complexidades para que melhor se possa medi-la (Biavaschi; Teixeira, 2018). É verdadeiro que as dificuldades de conceituar a terceirização e de medir seus impactos no mercado de trabalho são anteriores às duas leis de 2017 citadas. No entanto, a ampliação de seu uso e das formas burladas trouxeram maios complexidades e dificuldades, demandando redobrados esforços para a superação.

\section{O que é terceirização - conceito}

A terceirização, ${ }^{7}$ uma das formas de contratar que mais avançou no Brasil a partir dos anos1990 é, hoje, prática corrente em quase todos os segmentos econômicos, nas esferas pública e privada. Há terceirização sempre que um terceiro irrompe o binômio empregado $\mathrm{x}$ empregador, podendo se expressar tanto em situação interna quanto externa ao contrato de trabalho (Basualdo; Morales, 2014; Uriarte, 2006). Em regra, é uma estratégia das empresas para reduzir custos, partilhar riscos e aumentar a flexibilidade organizacional, trata-se de uma técnica de gestão. Segundo Krein (2007), pode ser encontrada, por exemplo, na contratação de: redes de fornecedores com produção independente; empresas especializadas de prestação de serviços de apoio; trabalho temporário via agências de emprego; pessoas jurídicas ou trabalhadores autônomos contratados para atividades essenciais; trabalho realizado no domicílio; cooperativas fraudulentas; deslocamento de parte da produção ou setores para ex-empregados.

\footnotetext{
7 As considerações sobre terceirização estão, em Parte, fundamentadas na pesquisa "A Terceirização e a Justiça do Trabalho", desenvolvida no CESIT/IE, incluídas no Relatório Científico apresentado à FAPESP em 30 de outubro de 2008. Consultar: BALTAR, Paulo. A terceirização e a Justiça do Trabalho. Campinas, 2008, Disponível em: https://www.trt4.jus.br/portais/media/431601/A terceirizaAcao_e_a_justiAca_do_trabalho_26deoutubrode2009.pdfAcessado em: $11 / 0 \overline{4} / 20 \overline{2} 1$.
} 
Nessa dinâmica, chega-se a presenciar o fenômeno da terceirização da terceirização, quando uma empresa terceirizada subcontrata outras ou outro, ou da quarteirização, com contratação de empresa com função específica de gerir contratos com as terceiras, formas essas, aliás, muito discutidas judicialmente. A terceirização pode estar encoberta por contratos de aparente natureza civil ou comercial, como os contratos de arrendamento, de fomento, facção, correspondentes bancários e, mais recentemente, também no setor bancário, as Franqs. Supostamente via de oportunidade destinada a ex-bancários "empreendedores", essas Franqs, ao lado dos correspondentes, ${ }^{8}$ têm contribuído para fragmentar a categoria e aprofundar a concentração bancária. Ainda, pode-se encontrar formas burladas de terceirização no disseminado loca-loca das plataformas digitais. Dessa forma, as expressões da terceirização, já presentes nas relações de trabalho, ganharam nova dimensão tanto com a reforma trabalhista, que a ampliou para quaisquer atividades e etapas do processo de trabalho, quanto com o "capitalismo de plataformas", sobretudo na pandemia quando o trabalho via plataformas digitais ganhou grande dimensão.

Uma das dificuldades para conceituar a terceirização pode estar na multiplicidade pelas quais aparece no mundo do trabalho, bem como na liberação irrestrita de seu uso. Liberação essa que a reforma trabalhista tratou de legalizar, retirando os freios colocados pela Súmula $\mathrm{n}^{\circ} 331 / 93$ do TST, ${ }^{9}$ permitindo que os empregadores definam o que e como será terceiri-

8 Vazquez, demonstra como o uso de correspondentes bancários se alastrou NAS relações de trabalho do setor financeiro, identificando-os como forma burlada de terceirização. Ver: VAZQUEZ, Bárbara V. Correspondentes bancários e terceirização: o subterrâneo das relações de trabalho no setor financeiro no Brasil, dissertação apresentada ao IE/ Unicamp para obtenção do título de mestre em desenvolvimento econômico, Campinas, 2018. Disponível em: <http://www.repositorio.unicamp.br/handle/REPOSIP/331802. Acesso em: 11.04.2021.

${ }^{9}$ Quando há decisões reiteradas sobre um mesmo assunto, o Tribunal pode consolidar essa interpretação em uma Súmula, uniformizando o entendimento jurisprudencial sobre aquele tema. As Súmulas do TST não têm efeito vinculante, mas podem ser impeditivas de recurso de revista, por exemplo, quando o acórdão do regional está de acordo com o entendimento que ela consagra. zado. E é para se dar conta dessa complexidade que se precisa abordá-la de forma ampla, nas concepções internas e externas ao contrato de trabalho, em diferentes atividades econômicas e ocupações, podendo, também, estar presente nas figuras dos "empreendedores", dos trabalhadores "por conta própria", nos informais, nos trabalhadores em plataformas digitais.

Trabalho elaborado ${ }^{10}$ no Centro de Estudos Sindicais e de Economia do Trabalho, CESIT/IE, objetivou quantificar o trabalho terceirizado no país. Esse estudo faz referência à Pesquisa da Atividade Econômica Paulista, $\mathrm{PAEP} / 1996$, que demonstra que $96 \%$ das empresas industriais que desenvolviam serviços especializados de assessoria jurídica contratavam o serviço de terceiros, quer de forma parcial ou integral. E, ainda, que 75\% das empresas industriais que prestavam serviços de processamento de dados e desenvolvimento de software na região metropolitana de São Paulo terceirizavam o serviço. O estudo refere, também, à Pesquisa Nacional por Amostra de Domicílios, PNAD, realizada pelo Instituto Brasileiro de Geografia e Estatística - IBGE entre os anos de 1995 e 2004, cujos dados demonstram que, considerado o total da ocupação no período, os postos de trabalho terceirizados formais foram os que mais cresceram.

Mas além de um conceito amplo de terceirização que incorpore as novas formas de uso da força de trabalho é, também, necessário um esforço para se buscar uma metodologia que permita medi-la com mais precisão, desafio que demanda aprofundamento dos estudos.

\section{Como medir a terceirização - metodologia e estado da arte}

As estatísticas têm sido limitadas para captar o fenômeno em sua amplitude e abran-

10 Márcio Pochmann, professor do IE/-UNICAMP, coordenou pesquisa sobre os trabalhadores terceirizados. No texto: Terceirização e diversificação nos regimes de contratação de mão-de-obra no Brasil, Campinas, agosto de 2006, s.ed., discute os principais aspectos da terceirização do emprego formal no Brasil. 
gência. Daí ser necessário recorrer a diferentes metodologias para que se possa ter um balanço mais aproximado sobre sua extensão, especialmente diante de sua ampliação para quaisquer atividades. Nesse sentido, busca-se identificar suas distintas manifestações e discutir as possibilidades metodológicas que mais nos aproximem desse fenômeno.

As pesquisas sobre terceirização se intensificaram no Brasil a partir dos anos 1990, em contexto de forte expansão dessa modalidade, sobretudo a partir da Súmula n ${ }^{\circ}$ 331/93 do TST, já referida. Contudo, esses estudos se mantinham circunscritos às análises setoriais dada à ausência de dados estatísticos e ao fato de que, mesmo para os setores em que a terceirização era permitida, nem todas as atividades eram terceirizadas. Enquanto isso, a terceirização avançava, sendo tratada, forma pouco crítica, como parte do fenômeno de desverticalização das plantas industriais e descentralização dos processos produtivos. Os próprios ganhos de produtividade eram atribuídos, por alguns autores, à externalização de parte da produção, elevando artificialmente a relação produto/número de horas trabalhadas (Considera; Valadão, 1995).

O tema ganhou visibilidade nos anos 2000, sobretudo em face de projetos de lei em andamento que tratavam de ampliá-la irrestritamente. Na prática, a terceirização já avançara para os setores industriais e, em parte, nos ปี processos produtivos desde a década anterior, - seja por meio da contratação de prestadoras de of empregados despedidos e contratados nessa $\underset{7}{ }$ modalidade. Mas as limitações estatísticas não ¿ permitiam medir com segurança sua amplituÆु de. As estatísticas oficiais, principais instru$\dot{m}$ mentos disponíveis, não captam essas novas expressões. Nesse sentido, as dificuldades para conceituar a terceirização antes focadas também se expressam em se adotar metodologia que permita melhor medir seu avanço.

As estatísticas oficiais brasileiras que medem o comportamento do mercado de tra- balho têm origem: nos registros administrativos do Ministério da Economia - ME; na Relação Anual de Informações Sociais - RAIS; no Cadastro Geral de Empregados e Desempregados - CAGED; nas pesquisas domiciliares do IBGE; no Censo demográfico; e, na Pesquisa Nacional por Amostra de Domicílios - PNAD que, desde 2012, substituiu a PNAD anual.

A RAIS mede o estoque de emprego formal ao final de cada ano e o CAGED a movimentação mensal (admitidos e desligados). Para ambos, está disponível um conjunto de variáveis que permitem identificar o número de trabalhadores por atividade econômica (Classificação Nacional de Atividades Econômicas - CNAE) e grupamento ocupacional (Classificação Brasileira de Ocupações - CBO) todos desagregados, bem como os tipos de vínculos. Entretanto, essas duas fontes não dispõem de variáveis que permitam identificar se o trabalho é realizado na condição de prestação de serviços para uma tomadora. Mesmo assim, aproximações são possíveis desde que se saiba quais são as atividades tipicamente terceirizáveis.

Até a aprovação da Lei $\mathrm{n}^{\mathrm{o}} 13.429 / 17$, a contratação de serviços na via triangular era circunscrita ao: trabalho temporário (Lei $n^{\circ}$ 6.019/74); serviços de vigilância (Lei $n^{\circ}$ 7.102/83) e de conservação e limpeza; serviços especializados ligados à atividade-meio do tomador, desde que inexistente a pessoalidade e a subordinação direta, vedada nas atividades-fim. Esse entendimento foi incorporado pela Súmula no 331 que, em dezembro de 1993, se sobrepôs ao do Enunciado n ${ }^{\circ}$ 256/1986 que, na prática, coibia as terceirizações. Para esse conjunto de atividades há na RAIS/CAGED com as seguintes descrições: i) temporários (tipo de vínculo); ii) serviços de vigilância (CNAE 801 e 802); iii) conservação e limpeza (CNAE 811 e 812); iv) outras atividades de serviços prestados às empresas (CNAE 829); v) locação de mão de obra temporária (CNAE 782); vi) seleção e agenciamento de mão de obra (CNAE 781); vii) fornecimento e gestão de recursos humanos para terceiros (CNAE 783). 
Ainda assim, as medições já se mostravam complexas, dado que não era possível atribuir trabalho terceirizado para todas as atividades a priori permitidas. Ainda, as pressões empresariais para liberar a terceirização para todas as etapas da estrutura produtiva já sinalizavam que essa forma de contratar avançava. Seu crescimento e sua ampliação para todos os setores deixava evidentes as limitações das análises que privilegiavam as atividades reconhecidas pela aplicação da Súmula $n^{\circ} 331$ ou por legislação específica.

Levantamento da produção cientifica sobre terceirização realizado por Marcolino (2019) apurou 235 teses e dissertações em que predominavam as pesquisas empíricas e setoriais. Essas mesmas pesquisas já indicavam a presença da terceirização em atividades finalísticas das empresas. Os resultados evidenciam realidade retratada em vários estudos e pesquisas, a saber: a terceirização é utilizada para reduzir custos e transferir as responsabilidades do tomador para o prestador de serviços ou, em última instância, para o próprio trabalhador, isso nos casos em que a contratação é realizada por Microempreendedor Individual - MEI ou PJ, como se tratará mais adiante.

Pesquisas mais abrangentes esbarraram na ausência de consistentes dados para medir o fenômeno. Em 2011, o Departamento Intersindical de Estatísticas e Estudos Sócio/econômicos, DIEESE, desenvolveu metodologia com base na RAIS, a partir da identificação das atividades tipicamente terceirizáveis. Segundo essa metodologia, 25,5\% dos assalariados com vínculos formais registrados pela RAIS em 2010 eram terceirizados (10,87 milhões de pessoas). Os resultados para os anos seguintes apresentaram pouca alteração: 25,5\% (2013) e 23,4\%(2018) (DIEESE, 2011).

Outra maneira de captar, via registros administrativos, é pela RAIS identificada. ${ }^{11}$ Conhecendo-se a prestadora de serviços e a to-

${ }^{11}$ A RAIS identificada permite desagregar o dado por empresa por meio do Cadastro Nacional de Pessoa Jurídica - CNPJ madora, tornam-se possíveis estudos comparativos sobre remuneração, jornada de trabalho, ocupação, entre outros. Trata-se de metodologia recomendável para estudos setoriais, com resultados que podem ser complementados com análises qualitativas sob condições de trabalho, saúde e segurança no trabalho, instrumentos coletivos, como foi a pesquisa sobre o setor aeroviário coordenada pelo CESIT no ano de $2016 .{ }^{12}$

O trabalho temporário, ainda que com previsão legal, tem sido, em regra, utilizado para encobrir contratos ilícitos, que extrapolam o permissivo legal. Relatos dão conta da presença de trabalhadores em linha de produção por vários anos, porém contratados por agências de locação de mão-de-obra. O estudo da evolução dos contratos temporários entre os anos 2017 e 2019 indica crescimento nesse tipo de vínculo de $28 \%$ e que os segmentos que mais os utilizam são o setor de serviços, embora tenha se constatado que, em 2019, 20\% desse tipo de vínculo foi absorvida pela administração pública, defesa e seguridade social. Além disso, em quatro ocupações estão concentrados $46 \%$ dos contratos temporários: trabalhadores em serviços administrativos; controle de manutenção e apoio à produção; vendedores e demonstradores; embaladores e alimentadores de produção. Embora não se possa associar o crescimento do trabalho temporário no último período (20172019) a aprovação da Lei. no $n^{0} 13.429 / 17$, mas certamente a lei facilitou para os empregadores as novas contratações por meio dessa modalidade, uma vez que a legislação citada alterou as condições de contratação do trabalho temporário, ampliando seu prazo de 90 para 180 dias, podendo chegar a 270 dias, e o estendendo para todas as atividades.

Dentre os esforços para estimar o comportamento da terceirização, cita-se metodologia proposta por Filgueiras para os registros administrativos, o CAGED (Filgueiras; Caval-

\footnotetext{
${ }^{12}$ Essa pesquisa analisou o perfil do emprego das principais empresas do setor aéreo brasileiro e as prestadoras de
} serviços para as mesmas ocupações. 
cante, 2015), baseada no cruzamento de setores econômicos em que as empresas se enquadram, CNAE, com as ocupações, CBO, contratadas em cada setor (Krein; Oliveira, 2019). Seguindo essa metodologia, adaptada para os anos de 2017 e 2019, selecionou-se o estoque para os dois anos e o saldo para a CNAE95 Seção. A CNAE "atividades imobiliárias, alugueis e serviços prestados às empresas" foi a que mais cresceu, gerando 285.474 novos empregos, ou seja, 44,6\% do total de empregos entre 2017 e 2019. A partir desse resultado, foram identificadas ocupações com maior incidência em 2019 e que, ao mesmo tempo, apresentam maior evolução entre 2017 e 2019. Os dados assim obtidos estão na Tabela 01, que mostra as ocupações mais destacadas: trabalhadores em serviços de manutenção de edificações; vendedores e demonstradores em lojas ou mercados; vigilantes e guardas de segurança; escriturários em geral; gerentes de marketing; comercialização e vendas; analistas de sistemas computacionais; almoxarifes e armazenistas; porteiros, guardas e vigias, ajudantes de obras civis, recepcionistas, como se pode ver:

Belchior (2018) no artigo: A terceirização precariza as relações de trabalho? O impacto sobre acidentes e doenças, desenvolveu

\begin{tabular}{|c|c|c|}
\hline \multicolumn{3}{|l|}{$\begin{array}{l}\text { Prestados às EmI } \\
\text { ias da CBO - no }\end{array}$} \\
\hline & Total & $(\%)$ \\
\hline $\begin{array}{l}\text { Trabalhadores nos serviços de ma- } \\
\text { nutenção de edificações }\end{array}$ & 54.872 & $19,2 \%$ \\
\hline $\begin{array}{l}\text { Escriturários em geral, Agentes, } \\
\text { Assist. e Aux. Administrativo }\end{array}$ & 52.616 & $18,4 \%$ \\
\hline $\begin{array}{l}\text { Vendedores e demonstradores em } \\
\text { lojas ou mercados }\end{array}$ & 33.851 & $11,9 \%$ \\
\hline $\begin{array}{l}\text { Analistas de sistemas computacio- } \\
\text { nais }\end{array}$ & 17.939 & $6,3 \%$ \\
\hline Porteiros, Guardas e Vigias & 13.942 & $4,9 \%$ \\
\hline Ajudantes de obras civis & 13.895 & $4,9 \%$ \\
\hline Recepcionistas & 11.899 & $4,2 \%$ \\
\hline Subtotal & 199.014 & $69,7 \%$ \\
\hline Total & 285.474 & $100,0 \%$ \\
\hline
\end{tabular}

metodologia com base nos dados da RAIS referentes ao ano de 2013, buscando identificar terceirizados a partir de outras informações. O primeiro passo do autor foi separar os que normalmente atuam em atividades terceirizadas e, após consulta realizada junto ao Sindicato dos Trabalhadores Terceirizados, algumas profissões/ocupações foram descartadas e outras acrescidas, compatibilizadas com a CBO e comparadas de acordo com a CNAE. A classificação com trabalhadores terceirizados foi realizada mediante atuação em setores de fornecimento de serviços para outras empresas ou locação de mão-de-obra.

O autor considerou não terceirizados os que atuam diretamente para a empresa contratante ou são donos de seu negócio. Resultado: 58 ocupações distribuídas em 31 atividades econômicas. A partir da base de dados por segmento de serviços, o autor chegou ao percentual de $21,3 \%$ de terceirizados sobre o total de ocupações selecionadas. Ou seja, para cada 10 trabalhadores naquela ocupação dois estavam em atividades tipicamente terceirizáveis. Em três CNAES concentrava-se 56,5\% das ocupações: vigilância e segurança privada; serviços combinados para apoio a edifícios, exceto condomínios prediais e limpeza em prédios e em domicílios, comparação com o período anterior a reforma (2016 -2018), os serviços combinados para apoio a edifícios cresceu $27 \%$ e serviços combinados de escritório e apoio administrativo, $35 \%$.

É importante destacar que a metodologia do autor foi construída com base em informações coletadas junto aos sindicatos o que limita o espectro dos trabalhadores terceirizados aos representados pelas próprias entidades consultadas, restringindo sua amplitude como demonstram os resultados alcançados: em torno de 3,6 milhões de trabalhadores terceirizados em 2013. Resultados que, aliás, sofreram pouca alteração na comparação com 2018. Ademais, o autor retira da condição de terceirizados os donos de seus próprios negócios, muitas vezes empregados burlados. 
Como se pode observar pelas metodologias apresentadas, estudos envolvendo registros administrativos são promissores para pesquisas mais desagregadas, desde que se tenha acesso à RAIS identificada e se conheça a tomadora e as prestadoras de serviços. Já pesquisas mais agregadas apresentam limitações concretas, especialmente após a "reforma" que ampliou a terceirização para todas as atividades. Se a empresa contrata terceiros para a execução de parte do processo de produção ou do processo produtivo completo, a contratada, nesse caso, pode ser classificada na mesma categoria econômica da contratante ou em uma classificação específica do serviço contratado, dificultando ainda mais os enquadramentos feitos para identificar a presença de trabalho terceirizado; ou seja, uma indústria metalúrgica poderá atuar dentro de uma montadora, uma empresa de engenharia em uma siderúrgica, uma empresa de transformados plásticos em uma farmacêutica e, assim por diante. Importante abordagem pode ser realizada por meio de pesquisas domiciliares, a seguir analisadas.

\section{As pesquisas domiciliares}

Em relação às pesquisas domiciliares, a PNAD-C permite auferir dados de mercado de trabalho mensais, trimestrais e anuais, o que não é possível por meio do Censo, este realizado a cada 10 anos. A PNAD-C mede todas as formas de contratação, sendo bastante útil para as pesquisas, especialmente quando se leva em consideração que o trabalho terceirizado não está restrito à contratação formal, mas presente em distintas modalidades de contratação, como é o caso, por exemplo, do trabalho por "conta própria" na forma de pessoa jurídica, MEI e autônomo, além da presença no emprego sem registro. A limitação se deve ao fato de que, também, para as pesquisas domiciliares não há distinção sobre as condições de realização do trabalho terceirizado. A única proximidade se refere ao item 04 que trata das características de trabalho das pessoas de 14 anos de idade ou mais. Contudo, sua utilização não é recomendada eis que não elaborada com essa finalidade: captar a prestação de serviços. Ainda assim, buscou-se captar algum aspecto dessa relação de trabalho.

[...] Na parte 4 - Características de trabalho das pessoas de 14 anos ou mais de idade, no item "4.2.1.1.3. Estabelecimento e local de exercício do trabalho principal" solicita ao informante que "identifique no trabalho principal o tipo de local em que funcionava o negócio/empresa” e se não tinha um estabelecimento para funcionar "onde exercia normalmente esse trabalho”, as opções oferecidas são as seguintes: (i) estabelecimento de outro negócio/ empresa ; em local designado pelo empregador, cliente ou freguês; em domicilio de empregador, patrão, sócio ou freguês; no domicilio de residência, em local exclusivo para o desempenho da atividade; no domicilio de residência, sem local exclusivo para o desempenho da atividade; em veículo automotor (taxi, ônibus, caminhão, automóvel, embarcações etc.; em via ou área pública e outros. (PNADC - manual de entrevista).

Exercício realizado para apurar os "por conta própria"13 indicou número expressivo $(57,4 \%)$ sem estabelecimento para funcionar e, desse total, 14.478.419, cerca de $42,3 \%$, funcionava em local designado pelo empregador, cliente ou freguês (6.127.584). Considerando-se sejam os "por conta própria" trabalhadores "por contra própria” quando ausente a figura do empregador é, no mínimo, curioso número tão elevado trabalhando em local designado pelo cliente. Da mesma forma, chama a atenção o alto número de pessoas trabalhando no domicílio do empregador (620.344). A desagregação por ocupação pode fornecer pistas mais concretas sobre a presença ou não de relações de emprego encobertas já que o guarda-chuva formal do "por conta própria", MEI, PJ, pode esconder uma relação de emprego.

Além disso, o trabalho "por conta própria” pode ser grande guarda-chuva para contrações via PJs, MEIs e trabalho autônomo,

${ }^{13}$ Esse exercício também pode ser aplicado para os trabalhadores com vínculos formais, 
Tabela 2 - Trabalhador por conta própria de 14 anos ou mais de idade por local de realização do trabalho (Brasil, 2012 a 2019) em \%

\begin{tabular}{l|c|c|c|c|c}
\hline & $\mathbf{2 0 1 7}$ & $\mathbf{2 0 1 8}$ & $\mathbf{2 0 1 9}$ & $\mathbf{2 0 1 7 - 2 0 1 9}$ \\
\cline { 2 - 5 } & \multicolumn{2}{|c|}{ Em que tipo de local funcionava esse negócio/ } \\
empresa?
\end{tabular}

expressando práticas de terceirização, com serviços que podem ser realizados interna ou externamente ao contrato e ao ambiente de trabalho. A desagregação por grupamento de atividades e ocupações podem ajudar a identificar a presença de trabalho terceirizado disfarçado por essas formas, na comparação com contratos formais, e avaliar possíveis movimentações entre os trabalhos com registro e os

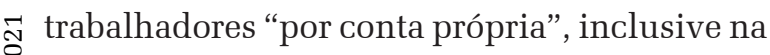
‥ presença ou não de empresa (com CNPJ) e conڤ tribuição previdenciária. Aliás, chama a aten¿ิ ção o crescimento de 30,1\% entre 2017 e 2020 fi dos "por conta própria” com CNPJ. Destes, o

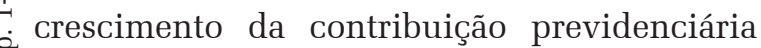
க் foi de 30.3\%. Esse quadro de maior legalidade

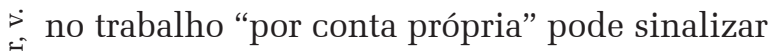
害 para atividades/ocupações "pejotizadas".

O refinamento dessa análise pode estar no aprofundamento de estudos que identifiquem, no trabalho por conta própria com CNPJ, as ocupações que mais cresceram no período, comparando-as com ocupações simi- lares no trabalho formal. Essas linhas de pesquisa podem ser desenvolvidas com base nas informações disponíveis, enfatizando que se trata de aproximações, já que não se dispõe de estatísticas específicas; e as metodologias que se tem, embora importantes, são insuficientes por não incorporarem o fenômeno em toda sua extensão. Nesse sentido, os diálogos com os institutos de pesquisa têm avançado lentamente. Talvez fosse importante se pensar em perguntas para a PNAD, o IBGE, que possam identificar os locais da contratação e da realização do trabalho, os diferentes comandos e de quem provém. Mas há dificuldades nessa elaboração. A própria Organização Internacional do Trabalho - OIT, na 19a Conferência sobre estatísticas do trabalho, emprego e trabalho subutilizado (ICLS), realizada no ano de 2013, quando atualizou as fronteiras do que é considerado trabalho, não considerou a possibilidade de recomendar aos países que se incluísse a terceirização. A aprovação irrestrita da terceirização por meio da Lei $n^{0}$ 13.429/17 
ampliou, ainda mais, as dificuldades para sua mensuração, eis que atividades consideradas finalísticas poderão ser terceirizadas, inclusive por meio de empresas que atuam em diferentes segmentos econômicos. Da mesma forma, a inclusão do "autônomo exclusivo" pela reforma trabalhista contribuiu para sua ampliação, transformando contratos a prazo indeterminado em PJ's, MEIs e autônomos, o que as medições antes indicadas não são capazes de captar. A forma mais eficiente de medir é por meio dos questionários, ajustando-os a essa nova realidade, e por meio de pesquisas setoriais que, embora necessárias e que precisam ser estimuladas, só captam uma parte do fenômeno. Importante também é se buscar analisar nos acordos coletivos disposições normativas envolvendo o fenômeno da terceirização.

\section{Terceirização e organizações sindicais: resistências e conquistas coletivas}

A análise de um conjunto de instrumentos coletivos dos anos de 2016 e 2019 (Teixeira, 2021) sugere que a autorização da terceirização irrestrita e a ampliação do contrato temporário foi absorvida por esses instrumentos de forma moderada, já que a ampliação entre 2016 e 2019 foi de $2 \%$ para uma amostra de instrumentos analisados. Essa expansão moderada sugere, de um lado, que a prática já vinha sendo adotada largamente, mesmo com as restrições da lei. Por outro lado, sua efetivação parece estar ocorrendo sem a participação sindical e, daí, deduzem-se dois movimentos distintos: 1) a terceirização como forma de contratação e estratégia empresarial foi incorporada pelo sindicalismo e, portanto, não há como resistir; e, 2) a incapacidade de o movimento sindical impor pauta mais reativa à terceirização. Ou os dois processos de forma simultânea, na linha das considerações de Belluzzo (2013) quanto à inevitabilidade (a-histórica, portanto) do fenômeno.

Os resultados da pesquisa também apontam que não houve adesão de novos segmen- tos econômicos após a aprovação da Lei $\mathrm{n}^{\circ}$ 13.429/17, e que a prática continua circunscrita aos setores e segmentos anteriores à legislação de 2017. Seus resultados também podem indicar que a contratação de serviços por meio de PJ's, MEI ou trabalho "autônomo" ganha força entre as novas modalidades de contratação propiciadas pela Lei $\mathrm{n}^{0} 13.429 / 17$, o que dificulta a ação dos sindicatos, na medida em que a prestação de serviços poderá estar sendo realizada fora do âmbito das empresas e, portanto, de mais difícil fiscalização e de busca de regulamentação por parte das entidades sindicais.

\section{CONSIDERAÇÕES FINAIS}

A avalanche neoliberal que chegou à América Latina na década de 1990, resistida em muitos de seus aspectos, voltou a produzir efeitos. Após 2016, sobretudo, reformas de corte ultraliberal, fundamentadas em rígido programa de ajuste fiscal, foram encaminhas. Muitas delas aprovadas pelo Parlamento a partir de promessas, como: melhorar a competitividade, gerar empregos, promover a retomada da atividade econômica e recuperar investimentos produtivos.

No caso da reforma trabalhista, ao argumento de assegurar segurança jurídica, atingiu as instituições públicas e, no caso da terceirização, postou-se na contramão da Súmula ${ }^{\circ}$ 331/93 do TST que definiu limites a essa forma de contratar. Além de transtrocar a fonte dos direitos dos trabalhadores, atribuindo prevalência aos contratos individuais, essa reforma legitimou formas de contratar até então consideradas fraudulentas e ampliou a terceirização para quaisquer atividades. Essa ampliação, aprofundando a cisão da classe trabalhadora, impactou negativamente suas organizações e, por decorrência, as negociações coletivas.

O texto mostra que, para melhor se compreender da terceirização, é importante abarcá-la nas complexidades pelas quais aparece no mundo do trabalho. A partir de exemplos 
e resultados de pesquisas, enfatiza a importância de se adotar conceito amplo que contemple suas expressões internas e externas ao contrato de trabalho, inclusive suas formas burladas, aliando esse esforço ao desafio de se construir uma metodologia para medi-la em suas múltiplas dimensões, visando a que se possa mais bem mapeá-la e analisá-la, inclusive para se possa pensar em um sistema de regulação que a todos incorpore.

O esforço de medi-la envolve uma compreensão entre as instituições de pesquisa sobre tal relevância. O texto trouxe algumas tentativas, avaliando-as em seus limites e possibilidades. Mas tanto em relação aos registros administrativos, quanto às pesquisas domiciliares, são possíveis alterações que propiciem o acesso a essas informações. O próprio IBGE introduziu recentemente no questionário, ainda em fase de testes, a identificação do contrato intermitente, modalidade de contratação incluída pela reforma trabalhista de 2017. Como esforço para se construir uma metodologia, tem-se sugerido a inclusão de perguntas no questionário a ser aplicado: se o trabalho é realizado por meio da contratação de empresa de prestação de serviços e a sua realização se dá em local indicado e distinto da empresa contratante. Quanto aos registros administrativos, a formulação pode ser ainda mais direta eis que são as próprias empresas que preenchem as informações: se a contratação é para atuar ปิ diretamente nas dependências da empresa ou para prestação de serviços em outra unidade de negócios. ti tante tanto para desnudar as falácias dos argu$\therefore$ mentos dos que defendem as reformas liberaliif zantes, quanto para trazer ao debate elementos

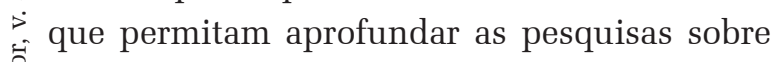
terceirização e seus impactos para as relações de trabalho e que possibilitem refletir sobre a importância de um sistema de proteção social ao trabalho alicerçado em um estatuto universal que a todos incorpore e em instituições públicas aptas a dar-lhe eficácia, colocando, assim, freios à ação predatória do capitalismo essencialmente desigualador.

Recebido para publicação em 18 de junho de 2021 Aceito em 20 de outubro 2021

\section{REFERÊNCIAS}

ALTVATER, Elmar. A crise de 1929 e o debate marxista sobre a teoria da crise. In: HOBSBAWM, Eric (Org). História do marxismo. Rio de Janeiro: Paz e Terra, 1987.

BALTAR, Paulo. A terceirização e a Justiça do Trabalho. Campinas, 2009. Disponível em: https://www.trt4.jus.br/ portais/media/431601/A terceirizaAcao e a justiAca do trabalho_26deoutubrodē2009.pdf. Acesso èm: 11/04/2021.

BALTAR, Paulo. A terceirização e a Justiça do Trabalho. Campinas, 2012. Disponível em: https://www.trt4.jus.br/ portais/media/431601/A terceirizaAcao e a justiAca do trabalho_26deoutubrodē2009.pdf. Acesso èm: 11/04/2021.

BASUALDO, Victoria, MORALES, Diego. (Org.). La tercerización laboral: orígenes, impactos y claves para su análisis en América Latina, Buenos Aires, Editorial Siglo Veintiuno, 2014.

BELCHIOR, C. A. $\square$ A terceirização precariza as relações de trabalho? O impacto sobre acidentes e doencas $\square$. Revista Brasileira de Economia, 62 (1), 41-60. Jan.-mar. 2018. Disponível em: https://www.scielo.br/j/rbe/a/6kyQnMZD P4QsbfWz7C9s9BQ/?lang=pt\&format $=$ pdf. Acesso em 15.06. 2021.

BELLUZZO, Luiz G. O capital e suas metamorfoses. São Paulo: UNESP, 2013.

BELLUZZO, Luiz G.; GALIPOLO, G. Manda quem pode, obedece quem tem prejuízo. São Paulo: Contracorrente, 2017

BELlUZZO, Luiz G. "O trabalho tem futuro "? Carta Capital, São Paulo. V.22 p.35

Jul./2020. Disponível em: https://www.cartacapital.com. br/artigo/o-trabalho-tem-futuro. Acesso em: 15.06.2021.

BERARDI, Franco. Fenomenología del Fin: sensibilidad y mutación conectiva. CABA: Caja Negra, 2020.

BIAVASCHI, Magda B. O direito do trabalho no Brasil, 1930-1942: a construção do sujeito de direitos trabalhistas. 2005. Tese (Instituto de Economia/Unicamp) - Programa de Pós-Graduação em Economia da Universidade Estadual de Campinas - Unicamp.

BIAVASCHI, Magda B. O direito do trabalho no Brasil 1930-1942: a construção do sujeito de direitos trabalhistas. São Paulo: LTr, 2007.

BIAVASCHI; Magda; BALTAR, Paulo. A Terceirização e a Justiça do Trabalho. Campinas, 2009. Digitado.

BIAVASCHI; Magda; BALTAR, Paulo. A Terceirização e a Justiça do Trabalho: diversidades regionais. Campinas, 2012. Digitado.

BIAVASCHI, Magda B; SANTOS, Anselmo Luis dos; DROPPA, Alisson. A dinâmica da experiência regulamentação da terceirização no Brasil: as súmulas do Tribunal Superior do Trabalho, os projetos de lei e as decisões do Supremo Tribunal Federal. Revista Política e Trabalho, $\mathrm{n}^{\circ} 41$, p 121-145,2014.

BIAVASCHI, Magda B; TEIXEIRA, Marilane. O. A terceirização e seu dinâmico processo de regulamentação 
no Brasil: limites e possibilidades. Revista da ABET, v. 14, n. 1, Jan/jun. 2015. Disponível em: https://periodicos. ufpb.br/index.php/abet/article/view/25700. Acesso em 15.06.2021.

BIAVASCHI, Magda B.; TEIXEIRA, Marilane O. A Reforma Trabalhista Brasileira na Dinâmica da Economia. Século XXI, Revista de Ciências Sociais, v. 8, no 2 , p. 477-518, jul./dez. 2018. Disponível em: https://periodicos.ufsm.br/ seculoxxi/article/view/36152. Acesso em 15.06.2021.

BIAVASCHI, Magda B.; TEIXEIRA, Marilane O.; DROPPA, Alisson. A importância do sistema público de regulação do trabalho: impactos da reforma trabalhista em diálogo com a economia e o direito. In: DELGADO, Gabriela N. (Org.). Direito Fundamental ao Trabalho Digno no Século XXI", LTr, São Paulo, 2020.

BIAVASCHI, Magda; DROPPA, Alisson; ALVES, Ana Cristina. A terceirização no contexto da reforma trabalhista e as decisões judiciais: Limites, contradições e possibilidades. In: QUEIROS, Renata; MACHADO, Sidney (Org). A construção jurisprudencial da reforma trabalhista pelo STF. São Paulo: Fi, 2021

BRAGA, José Carlos. Financeirização global. In FIORI, José Luís. Poder e Dinheiro: uma economia política da globalização. Petrópolis: Vozes, 1997.

CONSIDERA, Claudio; VALADÃO, Lucilia. Produtividade e emprego: questões econômicas e estatísticas - nota técnica. Boletim Conjuntural, IPEA, n.31, out.1995.

DEL BONO, Andrea; BULLONI, María Noel. El trabajo en plataformas digitales. Debates, Realidades y Desafíos. Editorial Miño y Dávila: Buenos Aires, 2019.

DIEESE. Departamento Intersindical de Estatística e Estudos Sócio econômicos; CUT, Central Única dos Trabalhadores. Terceirização e desenvolvimento: uma conta que não fecha. Sã̃o Paulo: Dieese; CUT, 2011. Disponível em: https://www.cut.org.br/system/uploads/ck/ files/Dossie-Terceirizacao-e-Desenvolvimento.pdf. Acesso em: 11.04.2021.

DRUCK, Graça. A Indissociabilidade entre Precarização Social do Trabalho e Terceirização. In: TEIXEIRA, Marilane Oliveira, ANDRADE, Helio R., COELHO, Elaine DÁvila. (Orgs.). Precarização e Terceirização - faces da mesma realidade. 1ed. São Paulo: Sindicato dos QuímicosSP, 2016, v. 1, p. 35-56.
FILGUEIRAS, Vitor A.; CAVALCANTE, Sávio M..Terceirização: debate conceitual e conjuntura política. Revista da ABET, v.14, (1), p15-36, 2015. Disponível em: http://periodicos.ufpb.br/ojs/index.php/abet/article/ view/25699/13875. Acesso em: 11.04.2021.

FILGUEIRAS, V. A.; CAVALCANTE, S. M. O trabalho no século XXI e o novo adeus à classe trabalhadora. PRINCÍPIO, São Paulo, v. 159, p. 11, 2020. Disponível em: https://revistaprincipios.emnuvens.com.br/principios/ article/view/19/12 Acesso em: 15.06.2021.

KREIN, José Dari. As tendências recentes na relação de emprego no Brasil: 1990-2005. 2007. Tese (Doutorado em Economia) - Programa de Pós-Graduação em Economia do Instituto de Economia da Universidade Estadual de Campinas. IE/UNICAMP.

KREIN, José D.; OLIVEIRA, Roberto V. Para além dos discursos: impactos efetivos da Reforma nas formas de contratação. In: KREIN, José D.; OLIVEIRA, Roberto V.; FILGUEIRAS, Vitor A. (Orgs) Reforma Trabalhista no Brasil: Promessas e realidade. Campinas, SP: Curt Nimuendajú, 2019.

OLIVEIRA, Francisco. Neoliberalismo à brasileira. In: SADER, Emir; GENTILI, Pablo. Pós-neoliberalismo: as políticas sociais e o Estado democrático.3. ed. Rio de Janeiro: Paz e Terra, 1996, p. 24-28.

TEIXEIRA, Marilane. Terceirização e trabalho temporário. In: KREIN José D.et.al. (Org.) Negociações coletivas pósreforma trabalhista (2017). Volume 2. São Paulo: CESIT, 2021

URIARTE, Oscar Ermida. Etica y Derecho del Trabajo. In: Revista electrònica de Dret del Treball i de la Seguretat Social. Barcelona: Universitat Pompeu Fabra. 01 de 2006 Disponível em: http://www.upf.edu/iuslabor/012006/ Latinoamerica.OscarErmida2.htm. Acesso em: 11.04.2021.

VAZQUEZ, Bárbara V. Correspondentes bancários e terceirização: o subterrâneo das relações de trabalho no setor financeiro no Brasil. 2018. Dissertação (Mestrado em Economia) - Programa de Pós-Graduacão em Economia do Instituto de Economia da Universidade Estadual de Campinas -IE/ Unicamp. Disponível em: http://www. repositorio.unicamp.br/handle/REPOSIP/331802. Acesso em: 11.04.2021. 


\section{OUTSOURCING IN THE CONTEXT OF BRAZIL'S LABOR REFORM: broad concept and methodology possibilities}

\author{
Alisson Droppa \\ Magda Barros Biavaschi \\ Marilane Oliveira Teixeira
}

\section{L'EXTERNALISATION DANS LE CADRE DE LA RÉFORME DU TRAVAIL: concept général et méthodologie}

\author{
Alisson Droppa \\ Magda Barros Biavaschi \\ Marilane Oliveira Teixeira
}

This paper is based on researches conducted at CESIT/Unicamp and brings to the light the need to adopt a broad concept for outsourcing, covering its internal and external aspects, the ones that are expressed and also the mocked ones. We discuss about the need to develop a methodology that allows a better and broader way to measure this form of hiring. Therefore, we approach some forms of measurement, suggesting a combination of initiatives to map them. We also discuss the impacts of outsourcing as approved by Brazil's Labor Reform, with no limits to any activity, which enlarges the difficulties to measure it, creating even bigger challenges for developing this methodology. From a set of instruments collected between the years 2016 and 2019, we analyze how outsourcing has been treated by this instruments, which suggests that unrestricted outsourcing and their enlargement with temporary contracts, has been absorbed in these negotiations.

KEywords: Outsourcing. Regulation. Employment Contract. Labor Reform. World of Work.
L'article, basé sur des recherches menées dans le cadre du CESIT/Unicamp, amène à la discussion la nécessité d'adopter une conception large de l'externalisation qui englobe ses aspects internes et externes, exprimés et moqués, ainsi que l'importance de chercher à construire un méthodologie qui permet de mieux et plus largement mesurer cette forme d'embauche. Pour ce faire, il aborde certaines des formes de mesure, en suggérant une combinaison d'initiatives pour la cartographier. Il aborde également les impacts de l'externalisation approuvée par la réforme du travail brésilienne sans limites sur aucune activité, augmentant les difficultés pour sa mesure, apportant de plus grands défis dans la recherche de la construction de cette méthodologie. Aussi, sur la base de l'analyse d'un ensemble d'instruments collectifs des années 2016 et 2019, il analyse comment l'externalisation était traitée par ces instruments, suggérant même que l'externalisation sans restriction et son expansion dans le contrat temporaire ont été absorbées dans ces négociations.

Mots-CLÉs: Externalisation. Régulation. Contrat de travail. Réforme du travail. Mondes du travail.

Alisson Droppa - Doutor em História Social do Trabalho. Trabalha com temas relacionados à terceirização dos serviços na América Latina, especialmente sobre as ações encaminhadas ao poder judiciário trabalhista. Publicou, entre outros textos, o livro: Direitos trabalhistas: legislação, justiça do trabalho e trabalhadores no Rio Grande do Sul (1958- 1964). 1. ed. Curitiba: Editora CRV.

Magda Barros Biavaschi - Doutora em Economia Aplicada pelo Instituto de Economia da UNICAMP. Professora do CESIT e do IFCH da Universidade Estadual de Campinas. Publicou, entre outros textos, o livro: O direito do trabalho no Brasil 1930-1942: construindo o sujeito de direitos trabalhistas. 01. ed. São Paulo: LTR, 2007

Marilane Oliveira Teixeira - Doutora em Ciências Econômicas pela UNICAMP. Pós doutoranda pelo CESIT/UNICAMP. Suas mais recentes publicações são: BIAVASCHI, Magda; TEIXEIRA, Marilane O.; DROPPA, Alisson. A importância do sistema público de regulação do trabalho: impactos da reforma trabalhista em diálogo com a economia e o direito”. In: Direito Fundamental ao Trabalho Digno no Século XXI, Gabriela Neves Delgado (Org.), LTr, São Paulo, 2020; O Trabalho pós-reforma trabalhista (2017) [livro eletrônico]: v. 1. Org. José Dari Krein [et al.]. São Paulo: Cesit - Centro de Estudos Sindicais e de Economia do Trabalho, 2021. 